\title{
Stimulating Innovation through Public Procurement: Barriers to Awareness Level of Public Procurement of Innovation
}

\author{
James Adu Peprah \\ School of Business, Takoradi Polytechnic, Takoradi \\ E-mail: jamespeprah2000@yahoo.com
}

Kwabena Nduro

School of Applied Arts, Takoradi Polytechnic, Takoradi

E-mail: highpriest31@gmail.com

John Mensah

School of Business, Cape Coast Polytechnic, Cape Coast

E-mail: jmjohnmensah@gmail.com

Received: September 2, 2015 Accepted: September 27, 2015

doi:10.5296/ber.v6i1.8824

URL: http://dx.doi.org/10.5296/ber.v6i1.8824

\begin{abstract}
Public sector procurement is very significant driver of innovation and currently re-emerging as the most sought after instrument of demand-side innovation policies. Progressively, it has been viewed as having imperative potential to drive innovation; there has been an issue of awareness deficit of public procurement as an innovation policy tool among key stakeholders- policy makers, procurement practitioners and academics particularly in Ghana and Africa. It's in this direction that this study sought to explore the barriers to awareness level of public procurement as an innovation policy tool among the key stakeholders in Ghana. The study adopted both exploratory and cross-sectional survey designs in investigating the barriers. Purposive sampling was used in selecting the sample to help fulfil the predetermined purpose of the study. The study revealed among others the following: low level of education as a major challenge to innovation in Ghana and developing nations,
\end{abstract}


limited budgets for education in training of high-skill specialist for promotion of innovation, lack of coordination across agencies on innovation policies (incoherent public policies), poor governance and business conditions affecting awareness level, lack of public sector support of innovation, no policy direction as to the use of public procurement to stimulate innovation in Ghana. The study also showed a lack of link between science and innovation in Ghana impeding the awareness level among the key stakeholders. The study recommends performance appraisal and institutional performance reviews for management of education to improve the level of education in Ghana and the curriculum for VTE level should be practical-oriented. They should also increase the funding of education in general and VTE in particular. Agencies responsible for STI should be strengthened to coordinate all policies intended to influence innovation in Ghana and put together a coherent policy competent enough to capturing innovation where public procurement policy, R\&D policies and innovation policies will be connected together.

Keywords: Ghana, Act 663, Public procurement, Public procurement of innovation, Barriers, Awareness.

\section{Introduction}

Public procurement accounts for a major proportion of the demand for goods, services and works in many nations. It is gradually accepted as an attractive tool for innovation and development for both developed and developing societies and nations. The size in terms of outlay of public procurement is quite considerable (Choi, 2009). According to Technopolis (2011) public procurement is a significant driver of innovation and at present re-emerging as the most sought after instrument of demand-side innovation policies in Europe. Its weight is mirrored in the often-cited fact that public procurement accounts $17 \%$ of the EU's GDP corresponding to more than $€ 2000 \mathrm{~b}$ (EC, 2010). Technopolis (2011) posits that the potential positive impact of innovation public procurement has been pointed out in numerous European level publications and the importance could also be seen in fostering more efficiency in the public sector and providing new solutions to societal challenges.

Public procurement in Africa according to Wittig (1999) account for up to 50\%-70\% of imports. Any improvements in the public procurement system can have a direct and beneficial effect on the overall economic situation of a country. Turley and Perera (2014) in South Africa reveal that public procurement spending represents 29 per cent of South Africa's GDP. From Daily Guide (2009) in Ghana, over 80 percent of state funds go into procurement after personal emoluments and that public procurement, which covers the purchase of goods, works and services constitute 14 percent of the country's Gross Domestic Product (GDP) and 24 percent of total imports. UNEP (2012) observed that many studies indicate that sustainable public procurement, which represents between 15 and 25 per cent of GDP, offers an incredible opportunity towards green innovation and sustainability. GoPrs/UNODC (2015) also writes that various studies emphasized the link between the efficiency of the national procurement system and the achievement of development goals. The prospective for this spending power can be leveraged to tackle the continent's development challenges is thus unbelievable. The efficient public procurement system offers numerous benefits which 
include innovation per the size and the policy space is favourable for public entities across the continent to move in this direction and address their political, social, economic and environmental priorities.

The significance of public procurement and the current thinking and action including research clearly mirror the intense attention to procurement and innovation as a secondary objective (African Development Bank \& African Development Fund, 2014). The earlier decade has shown substantial efforts to make structural and institutional alterations intended to assist drive innovation through procurement. There have also been serious attempts to modify the conception of how procurement is undertaken to deliver innovation, for various outcomes, including the promotion of new forms of service delivery, as well as the search for efficiencies (African Development Bank \& African Development Fund, 2014). The utilization of procurement as a 'tool for government' because of its size and volume is not new, nevertheless it has been conceptualised in diverse ways according to the politics, culture, and socio-economic context of the jurisdiction in question countries (African Development Bank \& African Development Fund, 2014). There is the recognition that a key role of innovation is not pertaining only in private sector, but also within public sector. This could and should harness the theory and practice of innovation to drive wealth creation and environmental sustainability. Public procurement is and has, often been used to promote objectives which are secondary to the primary vision of public procurement for instance applying public procurement to sponsor social, economical, industrial or environmental policies (Arrowsmith, Linarelli \& Wallace, 2000; Cane, 2004; Turpin, 1989). One typical example of using public procurement as a strategic government tool is the demanding of a systematic mobilisation of public procurement for the good of innovation and competitiveness (Edler, et, al., 2005). It has become clear that strong efforts are needed to mobilise procurement at all state levels for innovative markets (ibid) for an onward socioeconomic development. The developments in the global arena have been echoed by appreciation of the need to modernize public procurement systems by treating public procurement as a strategic government tool that affects directly the economy of a nation and quality of life of its citizens (Bolton, 2006).

Nevertheless, there has been an issue of awareness deficit of public procurement as an innovation policy tool among key stakeholders, policy makers, procurement practitioners and academics particularly in Africa. Georghiou et, al. (2014) indicate that there is lack of awareness of innovation potential or innovation strategy of procurement in organisations. Lember, Kalvet and Kattel (2011) also comment that lack of awareness exists among city officials about the connection between procurement and innovation, and local authorities tend not to be willing to take risks when promoting innovation through public procurement. From the European Research Area Board (2010) mentions that lack of awareness and unfamiliarity with the possibilities for procuring innovation and R\&D within the legal frameworks for procurement are still widespread. Ghana is not exception on the issue of lack of awareness on procurement innovations. Though Ghana has harboured the dream of swift social and economic development using knowledge and tools derived from Science and Technology ( $\mathrm{S}$ \& T) and Innovation (Ministry Of Environment, Science and Technology, 2009), there has 
been no remarkable progress in ensuring that Science, Technology and Innovation drive socio-economic activities in Ghana. A major cause is the absence of a definitive and prescriptive National STI policy document which defined the vision, goals, objectives and priorities for investment in STI (Ministry Of Environment, Science and Technology, 2009). It is in the light of this, that the study barriers of awareness level of public procurement as innovation policy tool in Ghana is being undertaken.

\subsection{Statement of Problem}

Governments are playing an important role as purchasers of innovations. Most governments around the world are using public procurement as an instrument to provide incentives for their states to develop and market innovative solutions to societal issues. Public procurement has progressively viewed as having important potential to drive innovation (Uyarraa, Edlera, Garcia-Estevezb, Georghioua, and Yeowa, 2014). This gives the governments the opportunity to promote market developments through public procurement, in which companies are challenged to opt for societal engagement and sustainability (SBIR, 2011). Despite the potential, there are barriers preventing the awareness of public procurement as an innovation policy to public sector from acting as an intelligent and informed customer. The inability on the part of key stakeholders to recognise the potentials of public procurement as an innovation policy tool in this part of the world is very detrimental to the speedily development of our nations. The promotion of innovation has not traditionally been a policy objective in the public sector (OECD, 2011). Hence the promotion of innovation through public procurement is newness and is by no means methodical practice. This, combined with risk-averse culture of the public sector, the lack of awareness of the potential of innovative public procurement in increasing productivity, as well as the lack of support and incentives hinders the consideration of innovation solutions (OECD, 2011).

The current Ghanaian public procurement regime does not integrate objective like innovation (Peprah, Nduro \& Mensah, 2015). It is therefore the desire of this study to inquire why or what is preventing the whole public sector organisations to appreciate the potentials of public procurement as an innovative policy tool. The general objective of the study is to contribute to the existing body of knowledge and research in the area of public procurement as innovative policy instrument by specifically investigating the barriers to awareness level of public procurement as an innovation policy tool among policy makers, practitioners, academics and supplier or contractors in Ghana.

\section{Literature Review}

\subsection{Empirical Review}

Researchers on innovation (Freeman, 1987; Lundvall, 1992; Nelson, 1993; Edquist, 1997) emphasise that it does not come about in isolation, but in interaction between persons, within firms, but also between firms, and between firms and knowledge-exploring organisations such as universities and research institutes (Coenen, 2006 as cited in Sörvik, 2010). Innovative public procurement is a growing drift in the discussion about technology policy. Lichtenberg (1988) tested the effect of non-competitive governmental contracts upon 
company sponsored $R \& D$ expenditures. He estimated that $1 \$$ increase in governmental sales induces 9.3 cents increment in private $\mathrm{R} \& \mathrm{D}$, while $1 \$$ increase in non governmental sales induces an increment of only 1.7 cents. This result suggests not only that public procurement has a positive effect on a firm's proclivity to engage in $\mathrm{R} \& \mathrm{D}$, but also that the demand pull effect is larger for public procurement than other private contracts (as in Guerzoni \& Raiteri, 2013). Likewise Geroski (1990) the role of public procurement in creating demand for new products and process, for making visible an already existing demand, and for providing a minimal market size in the early stage of an innovation. It clearly surfaces that the discussion of innovative public procurement is intrinsically linked with the debate about the role and magnitude of demand as a source of innovation (Guerzoni \& Raiteri, 2013).

The demand pull-hypotheses broadly studied in the Sixties and in the Seventies of the last century, were somehow left aside after the disrupting critique by Mowery and Rosenberg (1979) and Dosi (1982) mentioned Guerzoni and Raiteri (2013) which pointed at both theoretical and empirical flaws of the study in the area. A slow, but over time steady work about the demand side approach (Von Hippel, 1988; Malerba et al., 2007; Rogers, 1995; Fontana and Guerzoni, 2008) has given a new twist to this literature stream. Contextually, the resurrection of the demand side took also place both in the literature about industrial policy with the work by Edler and Georghiou (2007) "Public procurement and innovation. Resurrecting the demand side" and at the policy level (Georghiou, 2006; Aho et al., 2006; EU, 2010). Edler and Georghiou (2007) set up a very general framework of discussion, which grounds the need of demand oriented innovation policy in market failures as it is done for supply-oriented ones.

Public procurement of innovation also has been subject to some studies center overtly on management issues. According to Valovirta (2012) the managerial aspects have been most remarkably discussed in few recent studies focusing on risk management in innovation procurement (Tsipouri et al 2010, Kalvet \& Lember 2010). The management perspective together with a focus on innovation is also studied in recent work on procurement of complex performance (Caldwell \& Howard 2011 as cited in Valovirta, 2012). Valovirta posits that incorporating an innovation perspective in the procurement practice requires improving and expanding organisational capabilities and concluded on the study that public procurement of innovation needs to be embedded as an instrument in the broader framework of public service renewal. The study suggests a developing an innovation management approach to the public sector which encompasses public procurement as a central tool in acquiring innovative solutions to improve public services.

On developing nations, Kattel and Lember (2010) on public procurement as an industrial policy tool - an option for developing countries, argue that government procurement should not be seen only as an indirect support measure for development, but also as a direct vehicle for promoting innovation and industries and, thus, growth and development. Using public procurement for development assumes high levels of policy capacity, which most developing countries lack. The study concluded that if public procurement for innovation was to be seen as part of developing countries' industrial-policy portfolio, the accession to the GPA under current circumstances would not help. They sum their work by stating that public 
procurement as part of industrial policy has a lot more to offer for developing countries than the current discussion demonstrates. Another author on public technology procurement, Rothwell, outlines a situation consistent with life cycle theory, where developing regions are stuck with 'traditional' industries and non- R\&D performing branch plants as compared to the more prosperous regions where head offices and R\&D departments are situated. Public technology procurement is thus approached from an innovation policy perspective and as an instrument for helping developing regions to become more innovative. Rothwell lists several ways in which public procurement can stimulate innovations: the creation of new markets, creation of demand pull, and providing a testing ground for innovative products. He also discusses their implications for procurement activities. The paper concludes with some points on innovation oriented procurement practices (Rothwell, 1983).

While these studies on public procurement of innovation are highly significant for the topic at hand, they symbolize specific aspects to public procurement of innovation. There is a gap in the literature covering the broader aspects relating to what is preventing (barrier) developing nation like Ghana to be aware of the extent of capacity of public procurement to stimulate innovation.

\subsection{Barriers to Awareness of Public Procurement of Innovation}

Bjørnaas and Schmidt-Horix (2013) posit that the interest for public procurement as an instrument to stimulate innovation is growing and has a twofold account. The first is that governments have embraced the idea of an innovation policy, where different means are applied to spur innovative activity in the private sector, and through this gain competitive advantage over industries in other countries. The second reason for the interest is the changing role of public procurement. This is very significant for innovation as in term of policy tool, because there is a causal assumption that making procurement more strategic is related to its ability to contribute to innovation (Castaldi et al., 2011). Innovation researchers have provided empirical evidence of the impact on innovation of public procurement vis-à-vis traditional innovation policy instruments (Rothwell \& Zegveld, 1981; Geroski,1990; Aschhoff \& Sofka, 2009; Guerzoni \& Raiteri, 2012). Though studies have shown to extent the impact of procurement as something of a policy of universally remedy and repeated efforts to put procurement budgets to work to induce innovation, efforts have been met with limited success (NESTA, 2012 as cited in Uyarra, Edler Garcia-Estevez, Georghiou, \& Yeow, 2014). Various studies have attempted to investigate policy issues and barriers against the promotion and implementation of public procurement of innovation. In Ghana particular, there has been no notable progress in ensuring that Science, Technology and Innovation drive socio-economic activities. A major cause is the absence of a definitive and prescriptive National STI policy document which defined the vision, goals, objectives and priorities for investment in STI (Ministry Of Environment, Science and Technology, 2009). This study attempts to explore from the procurement environment what is/are preventing the promotion of public procurement of innovation.

Barriers to efficient execution of procurement of innovation include organisational, regulatory, skills and the inherent risk aversion of the public sector have been documented in the 
literature (Wilkinson et al., 2005 and Rolfstam, 2013). Bjørnaas and Schmidt-Horix (2013) again through literature revealed six possible barriers: lack of strategic function, lack of integration of the innovation process, lack of collaborative relationships with the suppliers, lack of culture for innovation; lack of cross-functional organisation, and lack of centralised purchasing. Their study concluded that all the possible factors were true as barriers with the exception of lack of centralisation, which they were not able to substantiate sufficiently. OGC (2004) and House of Lords (2011) conceive that a number of barriers can in turn prevent the public sector from 'capturing innovation'. These barriers include inadequate early warning, lack of engagement between procurers and suppliers, overly prescriptive and burdensome procurement processes, risk aversion, and procurement capability shortfalls ( as cited in Uyarra et al., 2014). Metcalfe and Georghiou (1997) identify four dimensions behind innovation in firms: the awareness of innovation opportunities, the capabilities to take hold of these opportunities, the set of resources they can command to innovate, and the incentive structures rewarding innovation. The Publin (2005) and Interact (2006) projects cited in Thenint (2010) also mapped different types of barriers for innovation, i.e. social, financial and technical phenomena that hinder innovation activities in institutions. Thenint (2010) in addition suggests that the following barriers are most frequently mentioned: professional resistance and heritage, absence or inadequacy of resources, public resistance to change, pace and scale of change, size and complexity, risk aversion and accountability, technical barriers, absence of capacity for organisational learning. These barriers have been observed or recounted through a series of case studies mostly in the UK, Ireland and Nordic countries and underscore the obstacles revealed earlier. These barriers are perceived depending from which environment you are coming from, developed or developing, sound political economy, democratic or undemocratic etc.

Complex Challenges Innovative Cities-CCIC (2013) on innovation in the public sector --state of the art report writes that people are recurrently cited in the context of barriers. It highlights a significant dimension of decision-making, which is frequently subjective, and also serves to remind that organisations depend on the people at every level of the pecking order. As a result, barriers might surface from the highest leadership levels, or at the middle-management level, or even during implementation. According to the report situation definitely will vary from one organisation to another and even from one unit or department to another within the same organisation. The report also mentioned political risks, as well as with the involved risks of implementing an innovation in general. That bears relevance to both resistances to change, and, in more general terms, to the unwillingness towards the management of uncertainties, which is so typical of most public sector organisations. The study report as well identified organisational culture, which is unsupportive of innovation, as a major obstacle for innovating in the public sector. And the lack of organisational (development) strategy, with a clear focuses on innovation. That suggests of the perceived importance of assigning strategic priority to innovation planning, as well as of the idea that innovation is generally the result of strategic planning and elaboration of how innovation relates, feeds into, and results from typical organisational activities, or how innovation itself is being pursued as a strategy for organisational change. The missing or ineffective communication with external stakeholders in the innovation cycle has also been stressed, pointing at the importance of networking, but 
also suggesting that public sector innovation is a collaborative process, which is not the product of a single organisation, department, or unit therein, and much less that of a single individual, regardless of how high he or she is positioned within the organisational hierarchy (CCIC, 2013).

Australian Public Service -APS on innovation in the public sector comments that there are barriers to procurement of innovation at every stage of the innovation processes which include: risk, short-term focus, failure of leadership, policies and procedures, efficiency and resources, and external opposition which can affect all phases. Skill sets and mobility, failed innovations, procurement requirements, recognition and feedback, measurement and impact can all affect generation with some impacting other phases as well. Divergent employment conditions can affect generation. Lack of champions and scrutiny can impact on all phases except generation. Policy, hierarchy, silos, and legislation can impact on the selection and implementation phases. Accountability and resistance can affect implementation and sustaining. Reluctance to let go impacts on implementation. Sustaining innovation affects sustaining. Identifying success factors affects sustaining and diffusion. It is apparent that there are common barriers so far, but can we say the same thing in Ghana? There is the gap of what is preventing Ghana from becoming aware of public procurement of innovation and this is what this study attempts to explore the barriers to awareness of public procurement as an innovation policy tool. We concluded that from empirical studies it is clear as revealed through i4g Secretariat of European Commission (2012) that powerful tools to foster innovation are specifically designed public procurements targeting innovations (PPI). Therefore, public procurement shall be utilised to arouse innovation and to create new markets. Awareness raising and changing the minds of procurers is essential to overcome the slow and timid application of PPIs and to fight barriers and risks associated with the change of procurement culture. As supported by Aubert (2004) on promoting innovation in developing countries states that innovation climates in developing countries are hampered by weaknesses of other key elements of knowledge-based economies as defined in the WBI framework, namely levels of educational attainment, the business environment and the information infrastructure. It is the desire of the study therefore from the barriers review to seek response from Ghana's perspective what is obstructing the awareness of public procurement as an innovation policy and to create the awareness of the potency of public procurement as an innovation policy instrument.

\section{Methodology}

\subsection{Research Design}

The study adopted both exploratory and cross-sectional survey designs in investigating the barriers to awareness of public procurement as an innovation policy tool among policy makers, practitioners, academics and suppliers/contractors. Exploratory because the study is about gaining insights and familiarity of public procurement of innovation from developing nation's perspective. It is mostly conducted about a research problem when there are few or no earlier studies to refer to (Cuthill, 2002; Catalano, \& Walker, 2002). Exploratory research is flexible and can address research questions of all types (what, why, how). Cross-sectional 
also provides a 'snapshot' of the outcome and the characteristics associated with it, at a specific point in time and focus on studying and drawing inferences from existing subjects, or phenomena (Lavrakas, 2008; Barratt, \& Kirwan, 2009).

\subsubsection{Population}

The population of the study is from the academic field of procurement, procurement entity, the suppliers/contractors to the procurement entity and the policy makers. The respondents were grouped into three. The academic field of procurement according to this study comprised of lecturers of Takoradi Polytechnic in the Purchasing and Supply Department both core and servicing related subjects and purchasing students from second and third years. The procurement entity comprised of the Procurement Unit of Takoradi Polytechnic and the Sekondi Takoradi Metropolitan Assembly- STMA Procurement Unit, the STMA directors and mangers referring to as the policy makers according to this study. The last element of the population as suppliers/contractors are suppliers or contractors to both procurement units of the entities mentioned above.

\subsubsection{Sample}

Base on the objective of the study the researchers chose the sample at the convenience (purposive sampling) of the researchers to help fulfil the predetermined purpose of this project. This means that the elements of study were chosen not through the application of statistical methods but because of their perceived information richness. The logic and power of purposive sampling derive from the emphasis on in-depth understanding. This leads to selecting information-rich case for study in depth. Information-rich cases are those from which one can learn a great deal about issues of central importance to the purpose of this research, thus the term purposive sampling (Patton, 2002). In this case the sample selected for this study includes lecturers of Takoradi Polytechnic in the Purchasing and Supply Department, both core and servicing related subjects and second and third year students of Purchasing \& Supply Department, Procurement Unit of Takoradi Polytechnic, the Sekondi Takoradi Metropolitan Assembly Procurement Unit, the suppliers/contractors from both procurement units of the entities mentioned above. The selection of the suppliers of both procurement units was done using simple random sampling. The sample for the study were procurement entity 43, supplier 23 and academics 183 totally up to 249.

\subsubsection{Research Instrument}

Data was collected from the various selected samples using survey questionnaires containing structured questions. The questionnaire was prepared thematically on the basis of the research objective. The questionnaire was divided into two segments. The first section; section A, deals with personal information of the respondents, while section B captures information in addressing the research objective.

\subsubsection{Reliability Test}

The Cronbach's alpha analyzed is used to test the reliability of questionnaires delivered to the respondents of the study to obtained their views and opinion of the statement. The result of 


\section{Macrothink}

Business and Economic Research ISSN 2162-4860 2016, Vol. 6, No. 1

crowbach's alpha is 0.891 . According to this result, it shows the questions/statements issued to the respondent are more reliable for this measurement of public procurement of innovation.

\section{Results and Analysis of the Study}

Under this section, the study discusses the data and interpretation processes. After gathering all the completed questionnaires from the respondents, the data was coded and entered into the computer for analysis using the Statistical Package for Social Sciences (SPSS) version 20 for windows. Descriptive statistics (frequencies and percentages) were computed for the objective.

\subsection{Demographic Features}

Table 1. Biographical Detail of Respondents

\begin{tabular}{|l|c|c|c|}
\hline Attributes & N & Frequency & Percentage \\
\hline Gender & 249 & & \\
\hline Male & & 127 & 51 \\
\hline Female & & 122 & 49 \\
\hline Age & 249 & & \\
\hline $18-24$ & & 137 & 55 \\
\hline $25-32$ & & 71 & 28.5 \\
\hline $33-40$ & & 30 & 12 \\
\hline $41-48$ & & 9 & 3.6 \\
\hline $49-56$ & & 2 & 8 \\
\hline Affiliation & 249 & & \\
\hline Procurement entity & & 43 & 17.3 \\
\hline Supplier & & 23 & 9.2 \\
\hline Academic & & 183 & 73.5 \\
\hline Education & 249 & & \\
\hline SHS & & 12 & 4.8 \\
\hline Diploma & & 189 & 75.9 \\
\hline Degree & & 30 & 12.0 \\
\hline Postgraduate & & 18 & 7.2 \\
\hline Professional Qualification & 249 & & \\
\hline CIPS & & 121 & 48.6 \\
\hline CILT & & 73 & 29.3 \\
\hline CISCM & & 37 & 14.9 \\
\hline Other Specify & & 202 & 7 \\
\hline Procurement Related Background & 249 & & \\
\hline Procure/supply chain management & & 47 & 18.9 \\
\hline Non procurement & & & \\
\hline & & & \\
\hline & & & \\
\hline & & & \\
\hline & & & \\
\hline & & & \\
\hline
\end{tabular}

Source: Field survey, 2015.

Table 1 on the bio data of the respondents' show that out of the total respondents surveyed 
there were 127 males representing 51\% and the female compatriots were 122 representing $49 \%$ showing that males were slightly more than the females. Given the slim difference in the numbers, one can say that the respondents were balanced in terms of gender. This show case the fact that results made cannot be referred as entirely biased towards one gender.

It can be inferred from Table 1 that, among the age ranges, majority of the respondents were within the age range of 18 to 24 which stood 137 representing $55 \%$ of the respondents, 25 to 32 had 71 representing $28 \%$ of respondents while 30 respondents representing $12 \%$ were within the ages of 33 to 40 . The age range of 41 to 48 was 9 representing $3.6 \%$ and 49 to 56 were 2 representing $8 \%$. This is an indicative of the fact that more young people are getting into procurement and it is a good sign of future for the industry. From the trend its evident that majority of the respondents find themselves in the economically active sector.

Also from Table 1 above on the respondents affiliation, procurement entity which constitute Procurement Unit of Takoradi Polytechnic and the Sekondi Takoradi Metropolitan Assembly Procurement Unit were 43 representing 17.3\%, the Suppliers were suppliers/contractors from both procurement units of the entities mentioned above stood at 23 representing $9.2 \%$ and lecturers of Takoradi Polytechnic in the Purchasing and Supply Department, both core and servicing related subjects and second and third year students of Purchasing \& Supply Department form the Academics were 183 representing 73.5\%. This shows that majority of the respondents were from the academics and also shows that all the affiliates are regular partakers in procurement activities and can truly offer good evaluation of the objective.

Table 1 on education indicates that, all the respondents selected were educated, it was found out that majority of the respondents were holders of Diploma, which constitute $75.9 \%$, followed by Degree holders constituting 30\%. Post Graduates constitutes 18\%, and SHS Certificate holders were in the minority with 12 representing $4.8 \%$. This demonstrates that all the respondents one way or the other are educated though the majority is coming from the those with diploma, all can actually give good assessment of the topic.

On the professional qualification of the respondents, those with CIPS stood 121 representing $48.6 \%$, those with CILT was 73 representing 29.3\%, CISCM was 37 representing $14.9 \%$ with other holding several professional qualification stood 18 representing $7.2 \%$. This demonstrates that respondents from the sample have variety of professional qualification among them the highest is CIPS. An indication that the majority of respondents for this research are professionally well trained in their diverse areas of work and makes their responses well informed ones. However the study did not specify either a respondent is chartered or not. Regardless of the educational levels of the respondents, the researchers find it very essential to find out the specific professional qualifications of the respondents in order to have a fair view of their capacity to awareness level of public procurement of innovation-PPI in Ghana. Procurement is a profession and for that reason required technical staff with procurement professional qualification and training in order to understand the reality of the topic.

Respondents' background in procurement and its related programs stood 202 representing $81.1 \%$ and non related procurement was 47 representing $18.9 \%$.This indicates that majority 
of the respondents aside partaking in procurement activities also pursued various programs in procurement, supply chain among others. This proves that the respondents have very good knowledge about procurement and its related programs and therefore gives a solid foundation as to what they provided to this study.

Table 2 below presents the summary of the views of respondents on the barriers to awareness level of public procurement of innovation in Ghana. It exhibits the mean ratings and standard deviation of each item on the scale where respondents were asked to indicate whether they agree or disagree on the items presented. The calculated means shows that low level of education is a major challenge to innovation in Ghana and developing nations (3.92), it was strongly followed by limited budgets for education in training of high-skill specialist for promotion of innovation (3.82), lack of coordination across agencies on innovation policies (incoherent public policies) (3.82) and poor governance and business conditions (3.82). Lack of public sector support of innovation got a mean of (3.69), with no policy direction as to the use of public procurement to stimulate innovation in Ghana had mean score of (3.64), also lack of link between science and innovation in Ghana affecting public policies had mean of (3.61). Lack of stable human resources reducing the ability of public institutions to play their role as efficiently as possible got a mean score of (3.56), disbelief about the benefits of procurement as a tool for economic growth in Ghana had a mean score of (3.47). Lack of information such as paucity of statistics on procurement and procurement of innovation score mean of (3.43) with no success program or project in Ghana on procurement of innovation to create awareness stood (3.40). The ability to take risk (risk aversion culture) obstruct innovation and the drive to do things better or more creatively had mean score of (3.35), innovation in Ghana is characterized by mediocre infrastructure got mean score of (3.34), with fragmentation among key stakeholders in different areas of public service constrain opportunities for innovation gotten (3.30), procurement R\&D is grossly underfunded stood (3.27) and weak science base got a mean score of (3.01).

Table 2. Descriptive Statistics of barriers to Awareness Level of Public Procurement of Innovation in Ghana

\begin{tabular}{|c|c|c|c|c|c|}
\hline Weak science base & 249 & 1 & 5 & 3.01 & 1.616 \\
\hline Lack of link between science and innovation in Ghana is affecting public policies & 249 & 1 & 5 & 3.61 & 1.480 \\
\hline Disbelief about the benefits of procurement as a tool for ecol & 249 & 1 & 5 & 3.47 & 1.574 \\
\hline Procurement R\&D is grossly under funded & 249 & 1 & 5 & 3.27 & 1.566 \\
\hline $\begin{array}{l}\text { Public expenditure decisions tend to emphasize short-term payoffs while procurement of } \\
\text { innovation R\&D investment are both long-term and risky }\end{array}$ & 249 & 1 & 5 & 2.97 & 1.394 \\
\hline on procurement of innovation to create awaren & 249 & 1 & 5 & 3.40 & 1.518 \\
\hline n Ghana and developing & 249 & 1 & 5 & 3.92 & 1.349 \\
\hline Limited budgets for education in training of high-skill specialist for promotion of innovation & 249 & 1 & 5 & 3.82 & 1.337 \\
\hline $\begin{array}{l}\text { Fragmentation among key stakeholders in different areas of public service constrain } \\
\text { opportunities for innovation }\end{array}$ & 249 & 1 & 5 & 3.30 & 1.423 \\
\hline $\begin{array}{l}\text { There is no policy direction as to the use of public procurement to stimulate innovatio } \\
\text { Ghana }\end{array}$ & 249 & 1 & 5 & 3.64 & 1.436 \\
\hline $\begin{array}{l}\text { Innovation in Ghana and developing nations are characterized by poor governance and } \\
\text { business conditions }\end{array}$ & 249 & 1 & 5 & 3.82 & 1.357 \\
\hline $\begin{array}{l}\text { The ability to take risk (risk aversion culture) obstruct innovation and the drive to do things } \\
\text { better or more creatively }\end{array}$ & 249 & 1 & 5 & 3.35 & 1.493 \\
\hline Ghana is characterized by mediocre infrastructure & 249 & 1 & 5 & 3.34 & 1.358 \\
\hline Lack of public sector support of innov & 249 & 1 & 5 & 3.69 & 0 \\
\hline
\end{tabular}




\begin{tabular}{|c|c|c|c|c|c|}
\hline $\begin{array}{l}\text { Lack of information such as paucity of statistics on procurement and procurement of } \\
\text { innovation }\end{array}$ & 249 & 1 & 5 & 3.43 & 1.275 \\
\hline $\begin{array}{l}\text { Lack of stable human resources reduce the ability of public institutions to play their role as } \\
\text { efficiently as possible }\end{array}$ & 249 & 1 & 5 & 3.56 & 1.349 \\
\hline Lack of coordination across agencies on innovation policies (incoherent public policies) & 249 & 1 & 5 & 3.82 & 1.325 \\
\hline Valid & 249 & & & & \\
\hline
\end{tabular}

Source: Field survey, 2015.

\subsection{Findings and Discussions}

Per the data presented the study revealed that low level of education is a major challenge to innovation in Ghana and developing nations. This is consistent with Aubert (2004) study that educational levels are low in developing countries, and, this is a momentous barrier to the development and diffusion of innovation in the developing countries. This finding also supports Maloney (2004) that there is correlation between educational levels and innovation performances. In Ghana's education, vocational enrolment has decreased by $1.3 \%$ and the disappearance of more than 50 institutions between the years 2011/12 and 2012/2013 (Ministry of Education, 2013). This drop according to the ministry would be the result of the low prestige of Vocational Education and the lack of demand from industry (ibid). Villalba (2007) study also shown that countries where there is higher interest in education particularly in vocational and training-VET are better performance in terms of labour and business activities in innovative sectors. And also suggested that countries where there is an interest for VET, there is a better market for innovation and companies seem to provide more innovative governance. This is not so in Ghana and therefore the ability to become aware, understand and create innovative ideas and products are affected. Still on education, the study also disclosed that a limited budget for education in training of high-skill specialist for promotion of innovation is also a barrier to awareness of public procurement of innovation in Ghana. This is very grave particularly for developing nation like Ghana and in confirming to limited budget, Education Finance Brief Ghana (2012) reported that between 2005 and 2012, the part of donors in the Ghanaian budget has dropped from 8.5 to $2.5 \%$ of the total education expenditure. This is deepening the rather a problem situation.

The study also showed that lack of coordination across agencies on innovation policies (incoherent public policies), poor governance and business conditions affect awareness level of public procurement of innovation among key stakeholders. This relates to the finding that there is fragmentation among key stakeholders in different areas of public service constrain opportunities for innovation. This validates the work of (Maher \& Andersson-OECD 1999) that poor governance has proved, in part, to be a major obstacle to improving the competitiveness of firms therefore affecting its innovative activities. The study further revealed that lack of public sector support of innovation is affecting the awareness level of procurement of innovation. The study produced evidence to the fact that there is no policy direction as to the use of public procurement to stimulate innovation in Ghana and this confirmed by Peprah, Ndruo and Mensah (2015) finding that the Public Procurement Act 663 used in conducting procurement activities in Ghana is not specifically designed to integrate objectives like innovation. The study pointed out that there is lack of link between science and innovation in Ghana. This finding is found to support Krauskopf, Krauskopf and Méndez 
(2007) study that developing countries doubt science as a tool for economic growth, for this reason, public policies to strengthen science and technology and promote the culture of innovation are, in general, weak and sometimes incoherent. This finding also corroborates with ICT4AD's (2003) report that there is weak scientific research base in Ghana which by and large encumbering the awareness level of public procurement of innovation.

The study also found out that lack of stable human resources reduce the ability of public institutions to play their role as efficiently as possible thereby affecting the awareness level of public procurement of innovation. It was as well established that lack of information such as paucity of statistics on procurement and procurement of innovation act as a barrier to awareness and where there are no success programs or projects in Ghana on procurement of innovation also hamper the awareness level among stakeholders. The ability to take risk (risk aversion culture) obstructs innovation and the drive to do things better or more creatively in Ghana is characterized by mediocre infrastructure.

\section{Conclusion}

Public procurement has been seen by many as one of the resurrecting instruments of innovation policy as compare to other instruments or tools but the awareness to that effect is not recognised in this part of the world (Ghana) even with its potential spread across the globe. There are barriers foiling the awareness of public procurement as an innovation policy tool to public sector from acting as an intelligent and informed customer in Ghana. Differing to previous studies that sought to fine the barriers of using public procurement as an innovation policy tool, we were able to explore barriers preventing key stakeholders of becoming aware of using public procurement to stimulate innovation. Per the major discoveries, the study can conclude the barriers affecting the awareness level of public procurement as an innovation policy tools are that the level of education is low with its limited budgets for training of high-skill specialist for promotion of innovation. There is also no coordination across agencies on innovation policies (incoherent public policies) which are because there is no sense of policy direction of using procurement to innovate. There is as well an issue of leadership from the point of poor governance and business conditions where there have been inadequacies of public sector support for innovation. From Ghana's perspective the demand for innovation across all sectors of the economy has turn out to be one of the main concerns to maintain both competitiveness and growth. Public sector procurement is the key source of demand for institutions and companies across the diverse sectors therefore effort must be deepen to remove all the barriers impeding the awareness creation among the key stakeholders. This has to deal with much education to the key stakeholders in the industry. The essence of awareness among stakeholders is necessity, where it helps to audit the process of that policy (public procurement of innovation). High awareness level makes implementation of a program or policy less difficult not only will it help you address existing requirements, but an excellence program will allow an institution or nations to adapt to new challenges quickly and efficiently.

However the study concede that its results cannot be generalized to other developing nations owing to the specific public procurement regime to Ghana and sampling method may not be 
an accurate indication of the whole public sector, both in terms of functional areas and geographically. It is thought that the recommendations can be targeted to eliminate the barriers to awareness level of public procurement of innovation among the developing nations.

\section{Recommendation}

The following specific recommendations are made based on the conclusion:

Education is the single-most imperative driver of economic empowerment for individuals, states and countries. With this, the authority in charge of education-- ministry of education should strengthen the monitoring systems and accountability measures which include performance appraisal and institutional performance reviews for management at ministry, agency, regional, district, school and institutional levels to improve the level of education in Ghana.

On the part of Vocational and Technical Education-VTE ministry of education should ensure that the curriculum to be used for VTE level should be practical-oriented. The ministry, government and donor countries should increase their funding of education in general and VTE in particular.

Government should boost largely the level of science, technology, research and development for innovation initiations in Ghana by strengthening the public research institutions, encouraging the aptitude of private firms to take up R \& D. Government should also promote and strengthen links between Science Technology and Innovation-STI related institutions and their business communities to improve their capabilities. Government should further strengthen and expand the provision of business development services and support for industrial firms undertaking and exploiting S\&T for innovation.

On the policy implication the agency responsible for Science Technology and Innovation-STI should be strengthen to coordinate all policies intended to influence innovation in Ghana and put together a coherent policy competent enough to capturing innovation where public procurement policy, R\&D policies and innovation policies will be connected together.

\section{Further Research}

This study recommends an increasing in the relative size of the sample across the country on the same topic to fully ascertain what the real situation is in the whole country-Ghana.

\section{References}

Abbey E. E. (2009, November 30). Procurement Claims 80\% State Funds'. Ghana Daily Guide

African Development Bank and African Development Fund. (2014). Innovations in Public Procurement-Comprehensive Review of the AFDB's Procurement Policies and Procedures'. Retrieved from http://www.afdb.org/procurementreview

Aho, E., Cornu, J., Georghiou, L., Subira, A. (2006). Creating an Innovative Europe. Report 
of the Independent Expert Group on R\&D and Innovation

Arrowsmith, S. L., Linarelli, J., \& Wallace, D. Jr. (2000). Regulating Public Procurement: National and International Perspectives'. London, UK: Kluwer Law International.

Aschhoff, B., \& Sofka, W., (2009). Innovation on demand-Can public procurement drive market success of innovations. Research Policy, 38(8): 1235-1247. http://dx.doi.org/10.1016/j.respol.2009.06.011

Aubert, J. E. (2004). Promoting Innovation in Developing Countries: A Conceptual Framework

Barratt, H., \& Kirwan, M. (2009). Cohort Studies: Design, Applications, Strengths \& Weaknesses of Cohort Studies, Retrieved from http://www.HealthKnowledge.org.uk

Bjørnaas, J.A. and Schmidt-Horix, H. (2013). Barriers to public procurement for innovation: A case study of ICT projects in the specialised health services in Norway, Thesis. Norwegian University of Science and Technology.

Bolton, P. (2006). Government Procurement as a Policy Tool in South Africa, Journal of Public Procurement, 6.

Cane, P. (2004). Administrative Law (4th ed.), London, UK: Oxford University Press.

Castaldi, C., Ten Kate, C. \& Den Braber, R., (2011). Strategic purchasing and innovation: a relational view, Technology Analysis \& Strategic Management, 23, 983-1000. http://dx.doi.org/10.1080/09537325.2011.616699

Choi. JW ( 2009). A Study of The Role of Public Procurement - Can Public Procurement Make Society Better?'

Complex Challenges-Creative Cities (CCIC) (2013). Innovation in the Public Sector State-of-the-Art Report, INTERREG IVC programme of the European Union.

Cuthill, M. (2002). Exploratory research: Citizen participation, local government, and sustainable development in Australia. Sustainable Development, 10(2), 79-89. http://dx.doi.org/10.1002/sd.185

Dosi, G. (1982). Technological paradigms and technological trajectories, Research Policy, 11(3), 147-162. http://dx.doi.org/10.1016/0048-7333(82)90016-6

Edler, J., \& Georghiou, L. (2007). Public Procurement and Innovation-Resurrecting the $\begin{array}{llll}\text { Demand } \quad \text { Side, } & \text { Research } & \text { 9olicy, } & \text { 36(7), }\end{array}$ http://dx.doi.org/10.1016/j.respol.2007.03.003

Edler, J., Ruhland, S., Hafner, S., Rigby, J., Georghiou, L., Hommen, L., Rolfstam, M., Edquist,

Edquist, C. (1997). Systems of innovation-Technologies, institutions and organizations '(pp. xiii-xiv). London: Pinter Publishers/Cassell Academic. 
Education Finance Brief, Ghana (Country Presentation) (2012). The Ten Policy Questions;' Addis Ababa

European Commission (2010). Communication "Europe 2020 Flagship Initiative Innovation Union" COM(2010) 546 final, 6.10.2010

Fontana, R., \& Guerzoni, M. (2008). Incentives and uncertainty: an empirical analysis of the impact of demand on innovation, Cambridge Journal of Economics, 32(6), 927-946. http://dx.doi.org/10.1093/cje/ben021

Freeman, C. (1987). Technology policy and economic performance': Lessons from Japan. London: Pinter Publishers.

Georghiou, L, Edler, J, Uyarra, E, Yeow, J, (2014). Policy instruments for public procurement of innovation:' Choice, design and assessment. http://www.sciencedirect.com/science/journal/00401625http://www.sciencedirect.com/scienc e/journal/00401625/86/supp/Chttp://dx.doi.org/10.1016/j.techfore.2013.09.018

Georghiou, L. (2006). Effective innovation policies for Europe-the missing demand-side, Report for the Prime Minister's Office of Finland, Economic Council of Finland.

Geroski, P. A. (1990). Procurement policy as a tool of industrial policy, International Review of Applied Economics, 4(2), 182-198. http://dx.doi.org/10.1080/758523673

Goprs.UNODC (2015). Public Procurement Corruption in Ghana'

Guerzoni, M., \& Raiteri, E. (2012). Innovative Procurement and R\&D Subsidies: Compounding Effects and New Empirical Evidence on Technological Policies in a Quasi-experimental Setting, Working paper No. 18/2012, Department of Economics "Cognetti de Martiis", University of Turin.

ICT4AD The Ghana ICT for Accelerated Development Policy (2003). A policy Statement for the Realization of the Vision to Transform Ghana into an Information-Rich Knowledge Society and Economy through the Development, Deployment and Exploitation of ICTs within the Economy and Society, Ghana

i4g Secretariat of European Commission (2012) 'Research \& Innovation Policy Workshop' Innovating out of the Crisis.' Workshop Report

Kattel, R., \& Lember, V. (2010). Public procurement as an industrial policy tool: An option for developing countries? J. Public Procurement, 10(3), 368-404.

Krauskopf,M., E Krauskopf, E., \& Méndez, B. (2007). Low awareness of the link between science and innovation affects public policies in developing countries: The Chilean case

Lavrakas P. J. (2008). Finite Population Correction (FPC) Factor: Encyclopedia of Survey Research Methods. London: Sage Publications. http://dx.doi.org/10.4135/9781412963947

Lember, V., Kalvet, T., \& Kattel, R. (2011). Urban Competitiveness and Public Procurement for Innovation, Urban Studies, $\quad 48(7), \quad 1373-1395$. 
http://dx.doi.org/10.1177/0042098010374512

Lichtenberg, F. R. (1988). The private $r$ and $d$ investment response to federal design and technical competitions. The American Economic Review, 78(3), 550-559.

Lundvall, B. Å. (1992). National Systems of Innovation: Towards a Theory of Innovation and Interactive Learning. London: Pinter Publishers.

Maher, M. and Anderson, T., (1999). Corporate Governance: Effects on Firm Performance and Economic Growth, OECD'

Malerba, F., Nelson, R. R., Orsenigo, L., \& Winter, S. G. (2007). Demand, innovation, and the dynamics of market structure: The role of experimental users and diverse preferences, Journal of Evolutionary Economics, 17(4), 371-399. http://dx.doi.org/10.1007/s00191-007-0060-x

Maloney, W. F. (2004). Informality Revisited, World Development, 32, 1159-78 http://dx.doi.org/10.1016/j.worlddev.2004.01.008

Metcalfe, J. S., \& Georghiou, L. (1997). Equilibrium and evolutionary foundations of technology policy, University of Manchester, Centre for Research on Innovation and Competition

Ministry of Education (2013). Report on Basic Statistics and Planning Parameters for Technical and Vocational Education In Ghana, 2012/2013 EMIS

Ministry of Environment, Science and Technology. (2009). National Science, Technology and Innovation Policy', Accra, Ghana.

Mowery, D. C., \& Rosenberg, N. (1979). The influence of market demand upon innovation. a critical review of some recent empirical studies, Research Policy, 8(2), 102-153. http://dx.doi.org/10.1016/0048-7333(79)90019-2

Nelson, R. R., \& Winter, S. G. (1982). An Evolutionary Theory of Economic Change. Harvard University Press.

NESTA, 2012. Plan I.' The case for Innovation-led growth.’ NESTA: London.

OECD. (2011). Demand Side Innovation Policy. OECD: Paris

OGC (2004) 'Capturing Innovation: Nurturing. Suppliers' Ideas in the Public Sector, Office of Government Commerce, London. www.ogc.gov.uk/documents/capturing_innovation.pdf

Patton, M. Q. (2002). Qualitative research and evaluation methods (3rd ed.), Thousand Oaks, CA: Sage.

Peprah, A. J, Nduro, K, \& Mensah, J. (2015) 'Stimulating Innovation through Public Procurement: The Level of Awareness among Key Stakeholders, Global journal of educational studies, ISSN 2377-3936, Vol. 1 No-2

Rogers, E. M. (1995). The Diffusion of Innovations, New York: Free Press. 
Rothwell, R. (1983). Creating a regional innovation-oriented infrastructure: The role of public procurement, Paper submitted to the Conference on Public Procurement and Regional Policy. University of Neuchâtel (31.19-1.11.1983)

Rothwell, R., Zegveld, W., (1981). Government regulations and innovation, in National Academy of Engineering (Ed.), Industrial innovation and public policy options:' report of a colloquium, National Academies Press: Gaithersburg, pp.116-147.

SBIR (2011).The power of public procurement: innovative solutions to societal challenges. NL Technopolis (2011). Trends and Challenges in Demand-Side Innovation Policies in Europe', Thematic Report 2011 under Specific Contract for the Integration of INNO Policy TrendChart with ERAWATCH (2011-12)

Thenint H. (2009). Labs for a more innovative Europe", GRIPS Workshop \#4 report, 12-13 October 2009, Copenhagen.

Tsipouri, C., \& Papadakou,L. M. (2005). Innovation and Public Procurement: Review of Issues at Stake.' Study for the European Commission (No ENTR/03/24), Fraunhofer Institute Systems and Innovation Research.

Tsipouri, L. et al. (2010). Risk management in the procurement of innovation: Concepts and empirical evidence in the European Union, Brussels: European Commission

Turley, L, \& Perera O. (2014). Implementing Sustainable Public Procurement in South Africa: Where to start, IISD REPORT

Turpin, C. (1989). Government Procurement and Contracts, London, UKAgency. The Hague

Sörvik, J, (2010). The Effects of Institutional Arrangements For Innovation In Clusters' - A Comparative Case Study Of Sugar Clusters In São Paulo, The North East Of Brazil And Cuba. The Research Policy Institute, Lund University, Sweden, ISBN 978-91-7473-065-4

Taylor, P. J., Catalano, G., \& Walker, D. R. F. (2002). Measurement of the World City Network, Urban Studies, 39(13), 2367-2376. http://dx.doi.org/10.1080/00420980220080011

UNEP. (2012). The Impacts of Sustainable Public Procurement': Eight Illustrative Case Studies. Paris: UNEP [Online] ATIE. Available: http://www.unep.fr/scp/procurement/docsres/projectinfo/StudyonImpactsofSPP.pdf

Uyarra E., Edler, J., Garcia-Estevez J., Georghiou, L., Yeow J., (2014). Barriers to innovation through public procurement': A supplier perspective, Technovation, http://www.sciencedirect.com/science/ article/pii/S0166497214000388

Villalba, E., (2007). On Creativity: Towards an understanding of creativity ant its measurements. JRC Scientific and Technical Reports 23561 EN.

Valovirta, V. (2012). Towards a management framework for public procurement of innovation. Paper presented at the Conference 'Demand, Innovation and Policy, Manchester Institute of Innovation Research, Manchester 22-23 March, 2012. 
Von Hippel, E. (1988). The source of innovation, Oxford University Press, New York

Wilkinson, R., Georghiou, L., \& Cave, J. (2005). Public Procurement for Research and Innovation, Office for Official Publications of the European Communities, Luxembourg

Wittig, W. A. (1999). Building Value through Procurement: A focus on Africa, A paper presented to the 9th International Anti-Corruption Conference. [On-Line]. Available at www.legacy.transparency.org

\section{Copyright Disclaimer}

Copyright for this article is retained by the author(s), with first publication rights granted to the journal.

This is an open-access article distributed under the terms and conditions of the Creative Commons Attribution license (http://creativecommons.org/licenses/by/3.0/). 